\title{
Optimization of Flocculation Process to Selectively Separate Iron Minerals from Rejected Iron Ultra Fines of Indian Mines and Minimize Environmental Issue
}

\author{
Manindra MANNA* \\ Research \& Development Department, Tata Steel, Jamshedpur, 831001 India. \\ (Received on May 28, 2018; accepted on January 10, 2019; J-STAGE Advance published date: March 8, \\ 2019)
}

\begin{abstract}
Indian iron ore mining industry disposes large amount of ultra fines containing high gangue minerals, thereby lead to loss of iron values and environmental pollution. Selective flocculation studies have been thought of for beneficiation of ultra fines. Response of different types of starches to iron ore ultra fines generated by the hydro-cyclone in Joda Iron Ore Washing Plants, Orissa, India has been studied. The starches used are: (i) maize starch (MS), (ii) potato starch (PS) and (iii) causticized potato starch (CPS). The order of selectivity as flocculant towards iron bearing minerals is observed as $\mathrm{MS}<\mathrm{PS}<\mathrm{CPS}$. This can be attributed to the different $\mathrm{C}-\mathrm{H}$ chain morphology of the starches. MS has more amylopectin than PS. Amylopectin adsorbed strongly onto all oxides minerals as carbonyl groups attached to C-2 and C-3 atoms of starch form surface complex with surface atom of all oxide minerals whereas amylose has a more adsorption tendency to hematite only. Amylose has less number of end groups than amylopectin, thus exhibiting lesser adsorption density than amylopectin. The selective adsorption characteristics of PS to hematite further improves by modification. Iron content and the iron recovery of the concentrate depend on flocculant dosage as well as settling time. A good concentrate is obtained suitable for pellet feed with Fe content in the concentrate increased from 57.8 mass $\%$ to 66.3 mass $\%$ and with an iron recovery of $66.5 \%$ by this process using CPS as a flocculating agent under optimized conditions. The tailing generated is suitable for building materials like tiles.
\end{abstract}

KEY WORDS: slime; flocculation; waste utilization; alumina removal; iron recovery.

\section{Introduction}

Huge quantity of iron fines is produced in India during mining operation and beneficiation process. The amount of such iron fines to be about $35 \%$ of the total iron ore produced. Now, India manufacture about 75 million tons of steel per annum and this capacity will rise in coming future. ${ }^{1)}$ So, more demand is expected for iron ore by steel manufacturer. Thus, a large quantity of iron fines will be generated and gradually accumulated with time. Huge land will be required for dumping such huge volume of iron fines which result in environmental problem. ${ }^{2)}$ Mining operation creates large amount of waste materials and tailings, which are disposed at the nearby slime pond as mine spoil dumps and becomes a continuous source of metal pollution to the soil, air and water resources of the area is concerned. The iron ore fines contain reasonably high $\% \mathrm{Fe}$, it is obvious that if properly beneficiated, these iron fines can be treated as a national resource rather than a waste. Chatterjee et al. ${ }^{3)}$ and Murty et al. ${ }^{4)}$ claimed that these fines contain high level $(15 \%)$ of gangue minerals which is responsible to make it

\footnotetext{
* Corresponding author: E-mail: manindra.manna@tatasteel.com DOI: https://doi.org/10.2355/isijinternational.ISIJINT-2018-382
}

soft in nature and cannot be used as feed material of blast furnace. Soft means change its shape during burden distribution which influences the decrease in gas permeability through the enlargement of cohesive zone in blast furnace (BF). High level of alumina in feed material might be responsible to hamper the productivity of blast furnace as high alumina slag is highly viscous and requires higher volume of flux (10 mass\% MgO). A large slag volume, resulting in higher coke rate and decrease productivity in blast furnace. As per calculation, a decrease of alumina content in the sinter from 3.1 to 2.5 mass $\%$ will improve RDI by at least six points, coke rate by $14 \mathrm{~kg}$ per ton of hot metal and $30 \%$ increase in its productivity. ${ }^{1-6)}$ Gururaj $^{7)}$ investigated that the gangue minerals are mainly montmorillite, kaolinite and illite. The alumina content of the slimes brought down in the beneficiated product will enhance (i) self-life of natural resources (ii) higher mine output with not much additional cost (iii) reduce environmental issues related to storage and dumping of fines and (iv) higher productivity by sinter plant. There are many beneficiation processes namely, gravity separation, ${ }^{8)}$ magnetic separation, ${ }^{9,10)}$ flotation $^{11-15}$ ) etc and techniques could, perhaps, be used for up gradation of these rejected ultra fines. As the rejected material is very fine in size, dispersion and flocculation ${ }^{16-20)}$ process 
can be thought to beneficiate of these materials and make suitable as feed material of blast furnace. The feed material is called ultra fines or very fines as around $73 \%$ mass of the feed material is below $1 \mu \mathrm{m}$ in size. In such scenario, utilization of such materials which may not require further reduction in size and minimize environment problem, the present research work has been taken. This paper reports the results of the dispersion study which shows that gangue minerals could be selectively dispersed leaving behind the valuable iron bearing minerals. This paper further, explains the results based on the surface charge of the particles. This paper reports the results on selective flocculation and separation process depending on types of starch used as flocculant, dosages and settling time and explains the interaction between the different types of starch and the iron bearing mineral substrate of the ultra fines.

\section{Experimental Procedures}

Iron ore fines were sampled from Joda slime pond in the state of orissa (India). The sample was first subject to disintegration and followed by sieving. 100 mesh screen was used for sieving purpose of the material. The analytical result of feed material and distribution of its particles size have given in Tables 1 and 2 respectively.

Table 3 shows the details about dispersing agent used and $\mathrm{pH}$ adjuster. Sodium hexametaphosphate (SHMP) of laboratory grade was used as dispersing agent and it was collected from Loba Chemie Pvt Ltd. Sodium hydroxide $(\mathrm{NaOH})$ of laboratory grade was used as $\mathrm{pH}$ adjuster and it was collected from Rankem Pvt Ltd.

Water used in the experiments was either distilled or collected from tap. The charge of fine mineral particles was measured by Delta Nano C zeta sizer based on theory of light scattering and electrophoretic mobility. ${ }^{20)}$ The predetermined amount of feed material was taken in a glass container and mixed with distilled water in such a way that the resultant mixture was 1 litre in volume and had the required ( 5 mass $\%$ ) pulp density. The solution was stirred by a magnetic stirrer for 10 minutes at $150 \mathrm{rpm}$ after addition of different dosages of dispersant. The liquor was then ready for addition of starch and allowed to settle for the

Table 1. Chemical analysis (mass \%) of feed material.

\begin{tabular}{cccc}
\hline $\mathrm{Fe}(\mathrm{T})$ & $\mathrm{Al}_{2} \mathrm{O}_{3}$ & $\mathrm{SiO}_{2}$ & $\mathrm{P}$ \\
\hline 57.8 & 7.55 & 7.15 & 0.143 \\
\hline
\end{tabular}

Table 2. Size wise $(\mu \mathrm{m})$ distribution of feed material.

\begin{tabular}{ccccc}
\hline$>25$ & $5-25$ & $1-5$ & $0.5-1$ & $<0.5$ \\
\hline 0 & 4.2 & 23.2 & 70.2 & 2.4 \\
\hline
\end{tabular}

Table 3. Dispersing agent and $\mathrm{pH}$ adjuster used before flocculation study.

\begin{tabular}{cccccc}
\hline $\begin{array}{c}\text { Dispersing } \\
\text { agent }\end{array}$ & Make & Dosages & $\begin{array}{c}\mathrm{pH} \\
\text { adjuster }\end{array}$ & Make & $\begin{array}{c}\mathrm{pH} \\
\text { adjusted }\end{array}$ \\
\hline$\left(\mathrm{NaPO}_{3}\right)_{6}$ & Loba Chem & $5000 \mathrm{ppm}$ & $\mathrm{NaOH}$ & Rankem & 8.5 \\
\hline
\end{tabular}

specific time. High turbidity ${ }^{20-23)}$ of the medium is responsible for no visible mud line and therefore the settling rates of the mixtures could not be measured. Settling time is the time allowed to the iron bearing minerals to form flocs preferably after addition of starch and settled down at the bottom of the experimental container as a concentrate. The supernatant was separated out by siphon and settled mass was accumulated. Both the separated materials were dried by oven heating and weighed after ensuring complete drying. The total $\mathrm{Fe}, \mathrm{Al}_{2} \mathrm{O}_{3}, \mathrm{SiO}_{2}$ and $\mathrm{P}$ contents in the final products were chemically analyzed and showed in Table 7. The represented results are the average of two experimental values and the variation is within $2 \%$ of the reported values. Dispersant was incorporated in the slurry material based on solid mass. The yield of iron value was measured.

Iron recovery can be calculated by the Eq. (1)

Iron recovery $=$

Mass of concentrate $\times \mathrm{Fe}(\mathrm{T})$ mass $\%$ in concentrate $\times 100 \%$

Mass of feed material $\times \mathrm{Fe}(\mathrm{T})$ mass $\%$ in feed

The agglomerated materials were crashed into powder form and analyzed by PANalytical X-Ray diffractometer to detect the probable compounds present in the concentrates and tailings. Around $1 \mathrm{~g}$ of dried material before and after flocculation study was disintegrated and placed in a mould. A mixture of $11 \mathrm{ml}$ biphenol A and $2 \mathrm{ml}$ of epoxy toughener was discharged above the material. The combination was vigorously mixed to eliminate any air bubble. The combination was then permitted to dry (either $1 \mathrm{~h}$ in vacuum or $6 \mathrm{~h}$ in open air) and the top of the toughened mass containing the dried material was brightened. After that, the toughened mass was under a carbon coating in empty space for $40 \mathrm{~s}-60$ $\mathrm{s}$ to create it electrically conductive and perceived under JEOL Electro Probe Micro Analyzer (EPMA).

\section{Results and Discussion}

\subsection{Characterization of Iron Ore Ultra Fines}

The fines of iron ore were accumulated from Joda slime pond in the state of Orissa, India. The material was analyzed by particle size analyzer and using SEM-EDS methods. It is evident from particle size analyzer that the major fraction of particles as shown in Table 2 is within $0.5 \mu \mathrm{m}$ to $5 \mu \mathrm{m}$ in size and therefore it has been thought to be a suitable material for selective flocculation process by which method gangue and iron bearing minerals can be separated. The SEM-EDS analysis ensures that such iron fines are well disintegrated (see Fig. 1) and both clay minerals and $\mathrm{Fe}$ containing minerals are distinctly identifiable.

Both minerals are very much co-related each other as after volcanic eruption iron bearing phase (hematite) is being contaminated with gangue minerals (clay) for a longer duration.

The X-ray diffraction (XRD) analysis of feed sample was regulated as received condition as well as after acid leaching to detect presence of gangue minerals in fines of iron ore. It is evident from the Fig. 2 that the fines of the iron ore consist of hematite $\left(\mathrm{Fe}_{2} \mathrm{O}_{3}\right.$, JCPDS card no. 33-0664, 19-0629 and 70-1522), goethite (FeOOH, JCPDS file 29-0713), 


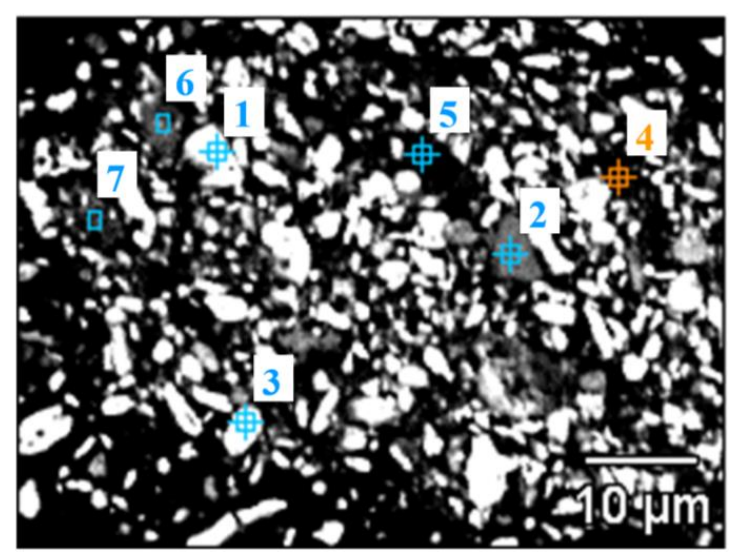

$(\operatorname{mass} \%)$

\begin{tabular}{|l|l|l|l|l|l|}
\hline & $\mathbf{O}$ & $\mathbf{A l}$ & $\mathbf{S i}$ & $\mathbf{P}$ & $\mathbf{F e}$ \\
\hline 1 & 29.09 & & & & 70.91 \\
\hline 2 & 30.69 & 5.44 & 0.72 & 0.45 & 62.70 \\
\hline 3 & 27.39 & 0.39 & 0.77 & & 71.45 \\
\hline 4 & 26.56 & 9.27 & 10.45 & & 53.71 \\
\hline 5 & 47.94 & 23.05 & 24.69 & & 3.99 \\
\hline 6 & 24.34 & 5.68 & 2.88 & & 63.26 \\
\hline 7 & 33.49 & 8.23 & 6.70 & & 51.58 \\
\hline
\end{tabular}

Fig. 1. Point SEM-EDS analysis in mass\% of iron ultra fines used as feed material. (Online version in color.)

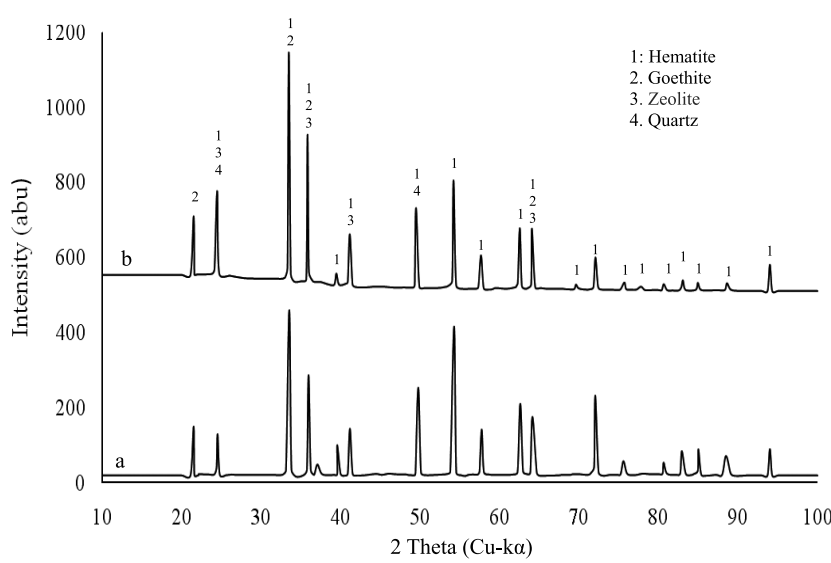

Fig. 2. XRD analysis result of iron ultra fines (a) feed material and (b) after concentrated hydrochloric acid leaching of feed material.

Table 4. Different phases present in feed material of iron fines analyzed by XRD techniques.

\begin{tabular}{cccc} 
& & \multicolumn{2}{c}{ (mass\%) } \\
\hline Hematite & Goethite & Zeolite & Quartz \\
\hline 81.45 & 3.56 & 14.64 & 0.35 \\
\hline
\end{tabular}

zeolite $\left(\mathrm{Na}\left(\mathrm{Si}_{2} \mathrm{Al}\right) \mathrm{O}_{6}, \mathrm{H}_{2} \mathrm{O}\right.$; JCPDS 19-1180) and quartz compounds (JCPDS 98-007-6582). Figure 2(a) indicates the XRD peaks of as received feed material whereas Fig. 2(b) indicates the XRD peaks after concentrated hydrochloric acid leaching of feed material.

No pure $\mathrm{Al}_{2} \mathrm{O}_{3}$ could be identified in the feed sample. The $\mathrm{Al}$ and $\mathrm{Si}$ content is constituted as alumina-silicate compounds. The mass $\%$ of different mineral phases present in the feed material was also analyzed by Rietvelt software and calculated results have been given in Table 4 .

\subsection{Dispersion Study}

Before flocculation study the iron ultra fines were well dispersed in water medium by adjusting $\mathrm{pH}$ and dispersing agent. Before selective flocculation process all particles must be in dispersed condition for better interaction of flocculating agent to specific mineral (here hematite is targeted mineral to form flocs and leaving the other gangue minerals in disperse condition) and improve the quality of yield. More negative zeta potential value of particles ensures that

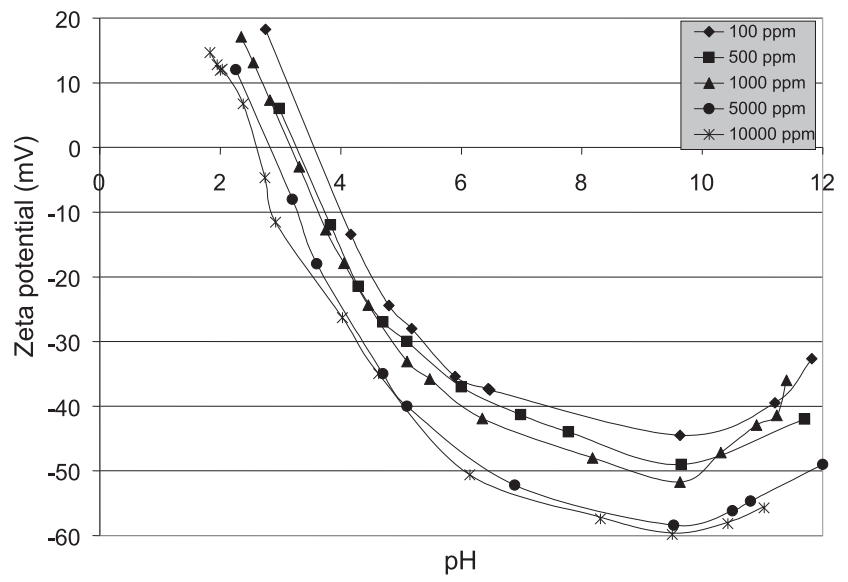

Fig. 3. Zeta potential characteristics of iron fines under varied $\mathrm{pH}$ and dispersing agents.

the particles will remain in disperse condition and may not get any chance to coagulate and settle down. Hence zeta potential result of iron fines is very important to ensure complete disperse condition of all the fine particles before selective flocculation process. It is seen from zeta potential characteristics as shown in Fig. 3 that the zeta potential is minimum under the condition of $\mathrm{pH}-8.5$ of the solution and dispersion dosage of $5000 \mathrm{ppm}$. The conditions have been optimized earlier and reported elsewhere. ${ }^{25)}$

\subsection{Effect of Different Starches}

It is evident from Fig. $\mathbf{4}$ that the separation process strongly depends on nature and dosages of the flocculants. Iron ore mainly consists of hematite $\left(\mathrm{Fe}_{2} \mathrm{O}_{3}\right)$, having average $\mathrm{Fe}-\mathrm{Fe}$ distance about 2.852 angstrom.

In a typical starch molecule, $\mathrm{O}_{\mathrm{I}} \mathrm{H}$ is the most polarizable among the four $\mathrm{OH}$ groups present. The distance between $\mathrm{O}_{\mathrm{I}} \mathrm{H}$ and $\mathrm{O}_{\mathrm{II}} \mathrm{H}$ is also around 2.85 angstrom. When the starch molecule approaches the $\mathrm{Fe}_{2} \mathrm{O}_{3}$ molecule, $\mathrm{O}_{\mathrm{I}}$ is likely to bind with available Lewis acid sites with $\mathrm{O}_{\text {II }}$ forming coordinate bond with adjacent $\mathrm{Fe}$ sites, thus forming a binuclear complexation. The performance of MS and PS are different and PS shows better selectivity compared to MS. This happens due to change in proportion (see Table 5) of amylose and amylopectin in MS \& PS. ${ }^{26)}$

Amylose is a linear molecule having molecular weight $10^{6}-10^{7}$, while amylopectin has branched structure containing several thousand cross-linked amylose chains (see 


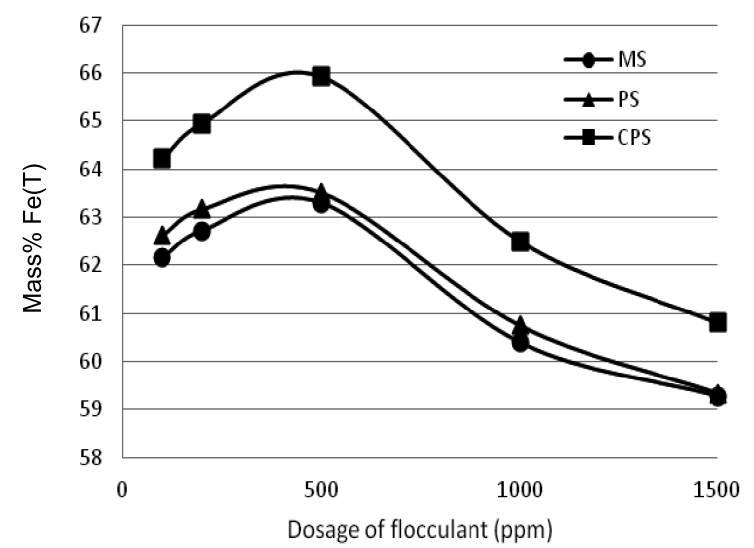

(a)

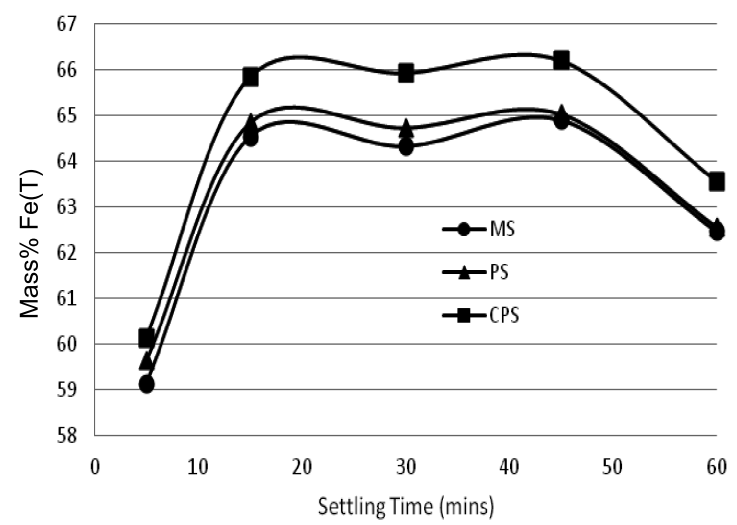

(b)

Fig. 4. Mass\% $\mathrm{Fe}(\mathrm{T})$ in concentrate under varied (a) flocculating agents (MS: Maize starch, PS: Potato starch \& CPS: Causticized potato starch) and dosages and (b) flocculating agents and settling times.

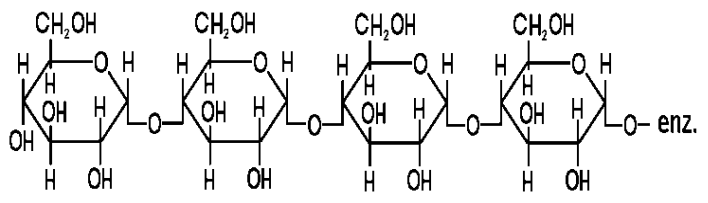

(a)

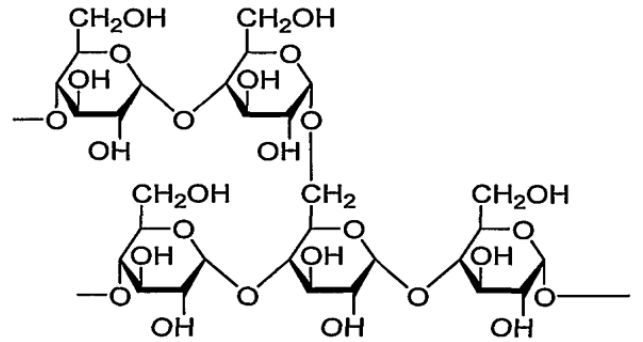

(b)

Fig. 5. Molecular structure of (a) amylose and (b) amylopectin.

Table 5. Percentage of amylose and amylopectin in MS and PS.

\begin{tabular}{ccc} 
& & $($ mass\%) \\
\hline Starch & Amylose & Amylopectin \\
\hline MS & 20.9 & 79.1 \\
PS & 26.9 & 73.1 \\
\hline
\end{tabular}

MS: Maize starch, PS: potato starch

Fig. 5) and molecular weight is 10 to 100 times higher than amylose.

Amylopectin is a better flocculant with greater recovery for different oxides but with amylose the product will be of better grade as amylose is responsible for selectivity toward hematite only. The higher molecular weight and highly branched structure of amylopectin was responsible for poor selectivity. Conformational change in the structure of starch occurs with change in $\mathrm{pH}$. Selectivity towards hematite of potato starch further improves by causticization. Therefore, causticized potato starch (CPS) significantly improves the iron level in the flocculated material to a quality of 66.3 mass\%. Slight improvement in quality of iron concentrate $[\mathrm{Fe}(\mathrm{T})=63.5$ mass $\%]$ is obtained using MS as flocculating agent, whereas, excellent quality of iron concentrate $[\mathrm{Fe}(\mathrm{T})=66.3 \mathrm{mass} \%]$ is expected to be obtained using CPS as a flocculating agent (Table 6).

Table 6 and Fig. 4(a) indicate two different aspects (i) iron recovery and (ii) $\mathrm{Fe}(\mathrm{T})$ content, Table 6 indicates how much iron is recovered from the feed material after selective flocculation process whereas Fig. 4(a) indicates what is the $\mathrm{Fe}(\mathrm{T}) \mathrm{mass} \%$ in the concentrate after selective flocculation
Table 6. Iron recovery from ultra fines for different starches under varied dosages.

\begin{tabular}{cccc}
\hline Dosages $(\mathrm{ppm})$ & MS & PS & CPS \\
\hline 100 & 19.25 & 19.66 & 20.25 \\
200 & 23.51 & 23.82 & 24.20 \\
500 & 40.31 & 40.70 & 41.92 \\
1000 & 58.61 & 59.03 & 60.21 \\
1500 & 71.71 & 72.19 & 70.40 \\
\hline
\end{tabular}

MS: Maize starch, PS: Potato starch, CPS: Causticized potato starch

Table 7. Iron recovery from ultra fines for different starches under varied settling times.

\begin{tabular}{cccc} 
& & & $(\mathrm{mass} \%)$ \\
\hline Settling time (mins) & MS & PS & CPS \\
\hline 5 & 9.65 & 9.88 & 10.21 \\
10 & 24.46 & 25.12 & 25.66 \\
30 & 40.31 & 40.71 & 41.91 \\
65 & 61.22 & 62.02 & 66.50 \\
60 & 72.89 & 73.77 & 74.63 \\
\hline
\end{tabular}

MS: Maize starch, PS: Potato starch, CPS: Causticized potato starch

process. For example, suppose all oxides minerals present in the feed material are in liberated condition, then 100 mass\% iron recovery is possible by optimized selective floccula- 
tion process but $\mathrm{Fe}(\mathrm{T})$ contain in the concentrate will be maximum 69.9 mass \% if hematite is the only iron bearing mineral present in the feed as well as finally in the concentrate. $\mathrm{Fe}(\mathrm{T})$ contain will be even less if other iron oxide (goethite) present in the feed and finally in the concentrate along with hematite.

The correlation between iron recovery and $\mathrm{Fe}(\mathrm{T})$ contain has been mentioned in Eq. (1).

There could be two possibilities for which the performance of the three flocculants are showing different performance: (i) the $\mathrm{C}-\mathrm{H}$ chain characteristics is shown in Figs. 6 \& 7 and Table 5.

Starch consists of amylose and amylopectin in the present case. MS has more amylopectin than PS. Amylopectin adsorbed onto all oxides minerals strongly due to the emergence of a surface multiplex between the carbonyl groups joined to C-2 and C-3 atoms of starch and surface atom of all oxide minerals whereas amylose has a more adsorbing tendency towards iron bearing minerals only. Amylopectin has more number of end groups than amylose, thus exhibiting higher adsorption density than amylose. The selective adsorption characteristic of PS to hematite is further improved by modification. The improvement in iron recovery by CPS may be explained in the light of the reduction of amylopectin adsorption caused by causticization. ${ }^{27,28)}$ As the amylopectin has been reported to be effective as a flocculant, the role of amylose has become more dominant in the process of selective separation. Nevertheless, syner-

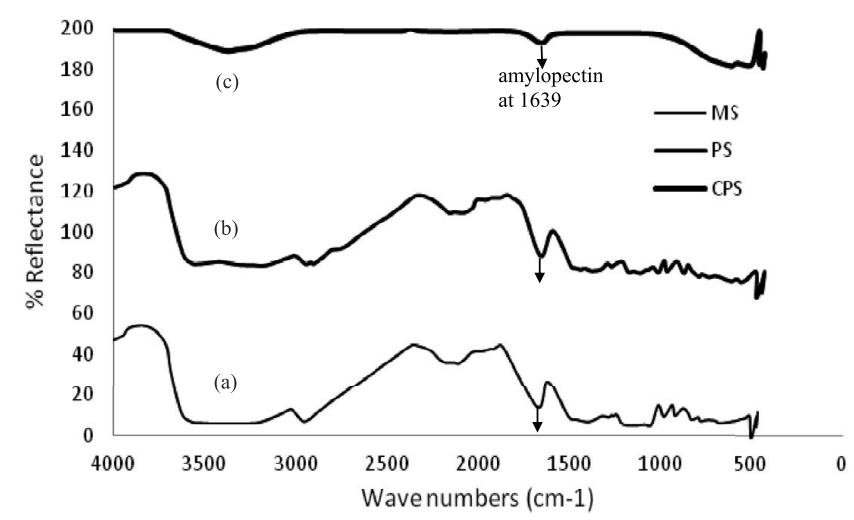

Fig. 6. FTIR analysis of different flocculating agents used, a: maize starch (MS), b: potato starch (PS) and c: causticized potato starch (CPS).

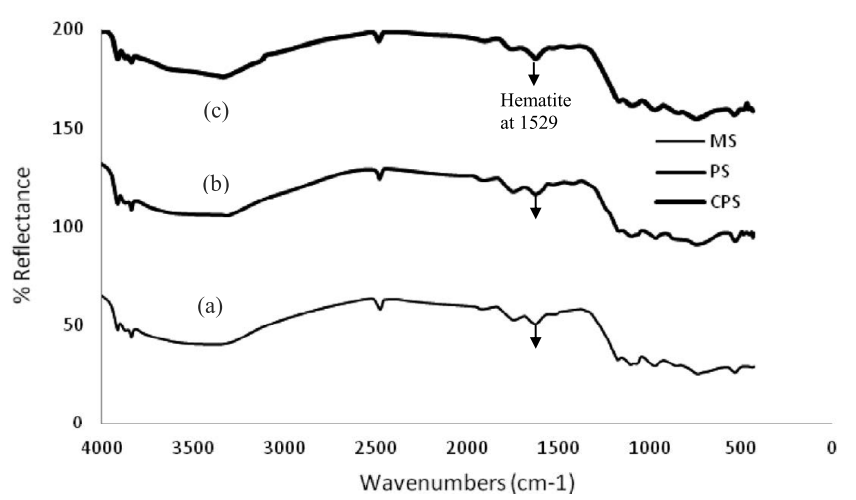

Fig. 7. FTIR analysis of different concentrates obtained when a: maize starch (MS), b: potato starch (PS) and c: causticized potato starch (CPS) used as a flocculating agent. gistic effect of amylose and amylopectin as pointed out by Weissenborn et al., 1996 also contributes towards selective separation. Figure 7 shows the FTIR results of different concentrates obtained after flocculation study using different flocculants. As iron, ultra fines are rejected material due to inferior quality, the reduction of gangue mineral is the most important aspect in the present study.

\subsection{Effect of Starch Dosages}

Figure 4 shows that with increase in dosage of starch, the quality of concentrate improves up-to a level of $500 \mathrm{ppm}$, with further increase in the dosage the concentrate quality deteriorated. High dosage indicates more starch available in the system for flocculation process whereas low dosage indicates less starch available in the system for flocculation process. With increase in the dosage of flocculant, the hematite particles preferentially adsorb the starch which results in higher grade of concentrate as the starch shows selectivity towards iron bearing minerals ${ }^{16-18)}$ when the concentration of the flocculant is more than a certain limit, there is a chance of entrapping gangue minerals in the flocs formed by the starch molecules as the amount of amylopectin increases in the system. ${ }^{29,30)}$

\subsection{Effect of Settling Time}

Iron recovery is found to increase with settling time (see Table 7).

With increase in settling time, more number of flocs settle along with larger particles also settle down due to gravity, resulting in increased iron recovery. Another interesting observation (see Fig. 4) was that, the Fe(T) level in the concentrate increased with increase in time, reached a maximum value at around 42-46 minutes, and steadily decreased thereafter. This may be because of the following reason- in the beginning large clay particles which were not stably dispersed settled down due to gravity, resulting in low grade of concentrate. Simultaneously, hematite particles were being preferentially adsorbed by the starch, resulting in the formation of flocs. After initial settling down of the larger particles along with the flocs, only flocs containing pure hematite were settling, resulting in better grade of concentrate. The poorer quality of the concentrate after certain time may be described as, the composite particles containing hematite as well as gangue minerals start settling due to comparatively weaker repulsive force of the composites as compared to the gangue minerals having stronger negative zeta potential.

\subsection{Characterization of Concentrate and Tailing}

Both the concentrate and tailing were analyzed by SEMEDS and XRD techniques. Figures 8(a)-8(c) shows SEM image of different concentrates obtained using MS, PS and CPS respectively.

It is found that the concentrates obtained using MS and PS as flocculating agents shows improvement in concentrate quality whereas the concentrate obtained using CPS as the flocculating agent gives significant improvement. EDX analysis has been done on few particles of concentrate to distinguish the phases. It is evident from Fig. 8 and EDX results that particles of gangue minerals are represented as black mass and iron bearing minerals are represented as 


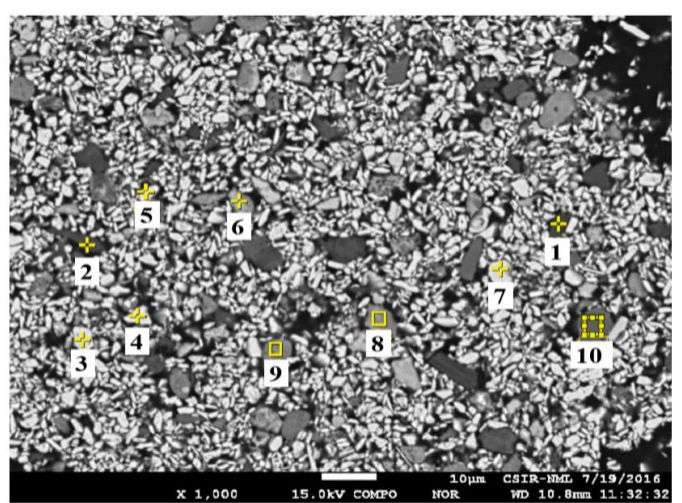

(a)

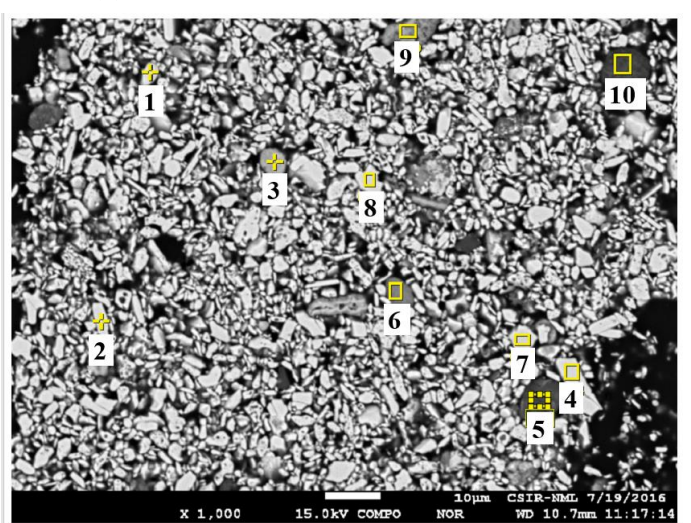

(b)

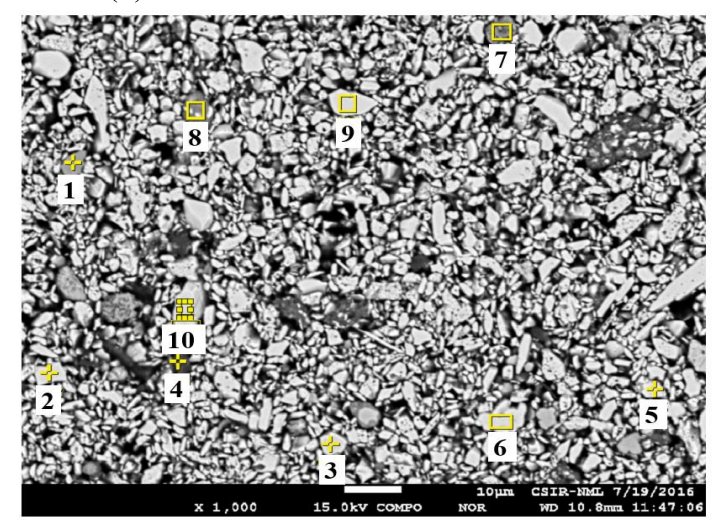

$\begin{array}{lllllll} & \mathrm{P} & \mathrm{Fe} & \mathrm{O} & \mathrm{Al} & \mathrm{Si} & \\ 001[[] & & 4.53 & 46.20 & 22.62 & 26.65 & \\ 002[] & & 4.19 & 45.10 & 23.69 & 27.02 & \\ 003[] & & 69.96 & 30.04 & & & \\ 004[] & & 69.16 & 30.84 & & & \\ 005[] & & 69.57 & 30.43 & & & \\ 006[] & 0.58 & 51.49 & 40.52 & 7.41 & & \\ 007[] & & 69.98 & 30.02 & & & \\ 008[] & 1.13 & 58.43 & 34.17 & 5.59 & 0.69 & \\ 009[] & 1.40 & 59.33 & 32.44 & 6.83 & & \\ 010[] & & 4.95 & 52.30 & & 42.75 & \\ \text { Average } & 1.04 & 46.16 & 37.21 & 13.23 & 24.28 & \\ \text { Standard deviation } & 0.21 & 13.03 & 4.77 & 2.86 & 9.23\end{array}$

$\begin{array}{lllllll} & \mathrm{P} & \mathrm{Fe} & \mathrm{O} & \mathrm{Al} & \mathrm{Si} & \\ 001[] & & 69.71 & 30.29 & & & \\ 002[] & & 68.44 & 30.19 & & 1.37 & \\ 003[] & & 65.85 & 32.97 & 0.61 & 0.57 & \\ 004[] & & 69.87 & 30.13 & & & \\ 005[] & & 8.72 & 60.92 & 30.36 & & \\ 006[] & 0.54 & 70.86 & 26.74 & 1.86 & & \\ 007[] & & 69.99 & 30.01 & & & \\ 008[] & & 70.13 & 29.87 & & & \\ 009[] & 0.99 & 57.90 & 36.20 & 4.91 & & \\ 010[] & & 3.95 & 51.07 & 21.30 & 23.68 & \\ \text { Average } & 0.76 & 55.54 & 35.84 & 11.81 & 8.54 & \\ \text { Standard deviation } & 0.16 & 16.31 & 4.82 & 4.25 & 8.74\end{array}$

(c)

$\begin{array}{lllllll} & \mathrm{P} & \mathrm{Fe} & \mathrm{O} & \mathrm{Al} & \mathrm{Si} & \\ 001[] & & 69.16 & 30.84 & & & \\ 002[] & & 70.01 & 29.99 & & & \\ 003[] & & 69.74 & 30.26 & & & \\ 004[] & & 11.54 & 53.85 & 34.61 & & \\ 005[] & & 70.09 & 29.91 & & & \\ 006[] & & 69.61 & 30.39 & & & \\ 007[] & 0.84 & 65.07 & 30.09 & 4.00 & & \\ 008[] & 0.63 & 61.72 & 32.60 & 4.48 & 0.58 & \\ 009[] & & 70.20 & 29.80 & & & \\ 010[] & & 71.13 & 28.87 & & & \\ \text { Average } 0.73 & 56.13 & 33.36 & 14.36 & 0.58 & \\ \text { Standard deviation } & 0.08 & 4.74 & 1.42 & 5.71 & 0.00\end{array}$

Fig. 8. Point SEM-EDS analysis in mass $\%$ of different concentrates obtained when (a) maize, (b) potato and (c) causticized potato starch used as a flocculating agent. (Online version in color.)

Table 8. The chemical analysis of concentrate and tailing.

\begin{tabular}{|c|c|c|c|c|c|c|c|c|}
\hline \multirow{3}{*}{ Starch } & \multirow{2}{*}{\multicolumn{4}{|c|}{ Concentrate }} & \multicolumn{4}{|c|}{$(\operatorname{mass} \%)$} \\
\hline & & & & & & & & \\
\hline & $\mathrm{Fe}(\mathrm{T})$ & $\mathrm{Al}_{2} \mathrm{O}_{3}$ & $\mathrm{SiO}_{2}$ & $\mathrm{P}$ & $\mathrm{Fe}(\mathrm{T})$ & $\mathrm{Al}_{2} \mathrm{O}_{3}$ & $\mathrm{SiO}_{2}$ & $\mathrm{P}$ \\
\hline MS & 64.89 & 3.13 & 3.02 & 0.065 & 49.30 & 12.84 & 12.08 & 0.236 \\
\hline PS & 65.02 & 2.81 & 2.82 & 0.062 & 48.93 & 13.37 & 12.47 & 0.243 \\
\hline CPS & 66.19 & 1.21 & 1.25 & 0.040 & 46.18 & 16.33 & 15.32 & 0.286 \\
\hline
\end{tabular}

MS: Maize starch, PS: Potato starch, CPS: Causticized potato starch

white mass. SEM image shows the concentrate obtained after selective flocculation using CPS is much richer with iron bearing minerals as compared to the other two concentrates.

It is further shown in Table 8 that CPS generates much superior quality concentrate under optimized conditions than in the cases of MS or PS.

The selective flocculation and dissociation method of iron fines using CPS as flocculating agent not only produce an extremely good quality product but also create a byproduct 
Table 9. Different phases present in concentrate and tailing analyzed by XRD techniques.

\begin{tabular}{|c|c|c|c|c|c|c|c|c|}
\hline & & & & & & & & ass \%) \\
\hline \multirow{2}{*}{ Starch } & \multicolumn{4}{|c|}{ Concentrate } & \multicolumn{4}{|c|}{ Tailing } \\
\hline & Hematite & Goethite & Zeolite & Quartz & Hematite & Goethite & Zeolite & Quartz \\
\hline MS & 90.23 & 2.36 & 6.53 & 0.88 & 68.82 & 6.22 & 22.84 & 2.12 \\
\hline PS & 91.86 & 2.21 & 5.25 & 0.68 & 68.24 & 6.58 & 23.21 & 1.97 \\
\hline CPS & 95.46 & 2.02 & 2.52 & - & 62.44 & 7.08 & 28.36 & 2.12 \\
\hline
\end{tabular}

MS: Maize starch, PS: Potato starch, CPS: Causticized potato starch

called tailing with more quantity of gangue minerals. The by-product with higher gangue and less Fe may be a good feed to make building material. The size of particles was coarser in concentrate than tailing. $\mathrm{X}$ ray diffraction study has been conducted on concentrate and tailing to quantify the presence of different phases. It is seen from Table 9 that the concentrate obtained after selective flocculation study consists of 92.5-98.5 mass\% iron bearing (hematite and goethite) and 1.5-7.5 mass \% gangue (zeolite and quartz) minerals whereas the tailing obtained after selective flocculation study consists of 70.5-75 mass \% iron bearing (hematite and goethite) and 25-29.5 mass \% gangue (zeolite and quartz) minerals.

This can be explained as amylopectin has a tendency for floc formation with iron bearing minerals whereas gangue minerals have higher degree of dispersibility. It is also evident from Table 8 that best concentrate with 98.5 mass \% iron bearing minerals can be obtained using CPS as a flocculating agent. This can be explained as, there is also a chance of adsorption on gangue minerals in the cases of PS and MS and subsequent floc formation. The adsorption of CPS on gangue minerals is reduced by causticization of potato starch and thereby CPS separates more efficiently iron bearing minerals only leaving the gangue minerals in dispersed condition.

\section{Conclusions}

(1) The effectiveness and efficiency for selective floc formation of iron fine particles strongly depends on nature of floc and dosages. From selectivity point of view, the PS is better than MS and best selectivity is obtained when CPS used as flocculent.

(2) Amylopectin adsorbs onto all oxides minerals strongly due to the emergence of a surface multiplex between the carbonyl groups joined to C-2 and C-3 atoms of starch and surface atom of all oxides minerals whereas amylose has a more adsorption tendency to hematite only. Due to different $\mathrm{C}-\mathrm{H}$ chain characteristics of the three different starches used in this exercise the nature of floc formation behavior is also expected to be varied.

(3) The $\mathrm{Fe}(\mathrm{T})$ level in the concentrate increased with increase in settling time, reached a maximum value at around 42-46 minutes, and steadily decreases thereafter.

\section{Acknowledgements}

The authors are grateful to Tata Steel Management for the kind consent to publish this research work in journal. Authors are also highly acknowledging Mr. K. K. Bhattacharjee and Dr Rajni Kant of NML, Jamshedpur, for surface charge calculation of iron fines and EPMA analysis of concentrate and tailing material. The kind help of Ms. Samvedna and Mr. V. Sharma for XRD and SEM-EDS analysis is also highly appreciated.

\section{REFERENCES}

1) Pradip: Trans. Indian Inst. Met., 59 (2006), No. 5, 40.

2) N. Chaturvedi and H. K. Patra: Int. J. Sci. Res. Methodol., 5 (2016), No. 1, 397.

3) A. Chatterjee, V. K. Lakshman, A. De and T. Mukherjee: Iron Steel Maker, 3 (1992), 87.

4) V. J. K. Ch. Murty, A. De, A. Chaterjee and V. S. Rao: Tata Search, 7 (1994), 20

5) L. Lu, R. J. Holmes and J. R. Manuel: ISIJ Int., 47 (2007), 349.

6) J. Pal, S. Ghorai, D. P. Singh, A. K. Upadhyay, S. Ghosh, D. Ghosh and D. Bandyopadhyay: ISIJ Int., 50 (2010), 105.

7) B. Gruraj, N. Prasad, T. R. Ramachandran and A. K. Biswas: Proc. 3rd Int. Mineral Processing Cong., Vol. 2, Elsevier, Amsterdam, (1981), 447.

8) R. O. Burt: Gravity Concentration Technology, Elsevier, Amsterdam, (1984), 456.

9) J. Svoboda: Magnetic Methods for the Treatment of Minerals, Elsevier, Amsterdam, (1987), 516.

10) J. W. Villar and G. A. Dawe: Min. Congr. J., 61 (1975), 40.

11) S. Prakash, B. Das, B. K. Mohapatra and R. Venugopal: Sep. Sci. Technol., 35 (2000), No. 16, 2651.

12) R. Houot: Int. J. Miner. Process., 10 (1983), 183.

13) A. Pindred and J. A. Meech: Int. J. Miner. Process., 12 (1984), 193.

14) S. Pavlovic and P. R. G. Brandao: Miner. Eng., 16 (2003), 1117.

15) A. E. C. Peres and M. I. Correa: Miner. Eng., 9 (1996), 1227.

16) L. Järnström, L. Lason and M. Rigdahl: Colloids Surf. A, 104 (1995), No. 2-3, 191.

17) L. Järnström, L. Lason, M. Rigdahl and U. Eriksson: Colloids Surf. A, 104 (1995), No. 2-3, 207.

18) L. Järnström, L. Lason and M. Rigdahl: Colloids Surf. A, 99 (1995), 11.

19) P. K. Weissenborn, L. J. Warren and J. G. Dunn: Colloids Surf. A, 99 (1995), 29.

20) H. O. Lien and J. G. Marrow: CIM Bull., 71 (1978), 109.

21) J. B. Farrow and J. D. Swift: Int. J. Miner. Process., 46 (1996), 263.

22) L. Guibai and J. Gregory: Water Res., 25 (1991), No. 9, 1137.

23) T. Tripathy and B. R. De: J. Phys. Sci., 10 (2006), 93.

24) M. Manna, S. Sasmal, P. K. Banerjee and D. K. Sengupta: Powder Technol., 211 (2011), 60.

25) M. Manna, S. Sasmal, P. K. Banerjee and D. K. Sengupta: ISIJ Int., 51 (2011), 1929.

26) D. Stawski: Food Chem., 110 (2008), 777.

27) K. Hanumantha Rao and K. S. Narasimhan: Int. J. Miner. Process., 14 (1985), 67.

28) M. A. Hughes: Solid-Liquid Separation, 3rd ed., Ed. by L. Svarosky, Butterworth \& Co (Publishers) Ltd, London, (1990), 74.

29) T. K. Wang and A. Audebert: J. Colloid Interface Sci., 119 (1987), No. 2, 459.

30) J. P. Friend and J. A. Kitchener: Chem. Eng. Sci., 28 (1973), 1071. 